\title{
Oncologic Outcomes and Risk Factors for Recurrence after Tumor-specific Mesorectal Excision of Rectal Cancer:
} 782 Cases

\author{
Sam Hee Kim, Ki Beom Bae, Jung Min Kim, Jae Ho Shin, Min Sung An, Tae Geun Ha, Sung Mok Ryu, \\ Kwang Hee Kim, Tae Hyeon Kim, Chang Soo Choi, Jin Yong Shin ${ }^{1}$, Minkyung $\mathrm{Oh}^{2}$, Seung Hun Baek², \\ Kwan Hee Hong
}

Department of Surgery, Busan Paik Hospital, ${ }^{1}$ Haeundae Paik Hospital, and ${ }^{2}$ Clinical Trial Center in Pharmacology, Inje University College of Medicine, Busan, Korea

Purpose: The aim of this study was to analyze the oncologic outcomes and the risk factors for recurrence after a tumor-specific mesorectal excision (TSME) of resectable rectal cancer in a single institution.

Methods: A total of 782 patients who underwent a TSME for resectable rectal cancer between February 1995 and December 2005 were enrolled retrospectively. Oncologic outcomes included 5-year cancer-specific survival and its affecting factors, as well as risk factors for local and systemic recurrence.

Results: The 5-year cancer-specific survival rate was $77.53 \%$ with a mean follow-up period of $61 \pm 31$ months. The overall local and systemic recurrence rates were $9.2 \%$ and $21.1 \%$, respectively. The risk factors for local recurrence were $\mathrm{pN}$ stage $(\mathrm{P}=0.015)$, positive distal resection margin, and positive circumferential resection margin $(\mathrm{P}<0.001)$. The risk factors for systemic recurrence were $\mathrm{pN}$ stage $(\mathrm{P}<0.001)$ and preoperative carcinoembryonic antigen level $(\mathrm{P}=0.005)$. The prognostic factors for cancer-specific survival were pT stage $(\mathrm{P}<0.001)$, pN stage $(\mathrm{P}<0.001)$, positive distal resection margin $(\mathrm{P}=$ $0.005)$, and positive circumferential resection margin $(\mathrm{P}=0.016)$.

Conclusion: The oncologic outcomes in our institution after a TSME for patients with resectable rectal cancer were similar to those reported in other recent studies, and we established the risk factors that could be crucial for the planning of treatment and follow-up.

Keywords: Rectal neoplasms; Colorectal cancer recurrence; Oncologic outcome; Tumor-specific mesorectal excision

\section{INTRODUCTION}

The treatment of rectal cancer is made difficult by its higher local

Received: August 25, 2011 Revised: September 28, 2011

Accepted: October 23, 2011

Correspondence to: Kwan Hee Hong, MD

Department of Surgery, Busan Paik Hospital, Inje University College of

Medicine, 75 Bokji-ro, Busanjin-gu, Busan 614-735, Korea

Tel: +82-51-890-6349, Fax: +82-51-898-9427

E-mail: gskhh@ijnc.ac.kr

This article was presented at a Meeting of the Korean Society of Clinical Oncology on March 5, 2011.

(C) 2012 The Korean Society of Coloproctology

This is an open-access article distributed under the terms of the Creative Commons Attribution NonCommercial License (http://creativecommons.org/licenses/by-nc/3.0) which permits unrestricted noncommercial use, distribution, and reproduction in any medium, provided the original work is properly cited. recurrence rate, deep pelvic location, and need for more complicated adjuvant chemoradiotherapy (NCRT). Furthermore, surgical treatment combined with chemoradiotherapy is associated with many problems, such as permanent colostomy and urinary and sexual dysfunction, which reduce patients' quality of life. Therefore, careful consideration is required before starting treatment for rectal cancer. The local recurrence rate, which has been a major problem in the surgical treatment of rectal cancer, was as high as $24 \%$ in research conducted by the German Rectal Cancer Study Group and the Gastrointestinal Tumor Study Group (GITSG) [1, 2]. However, the addition of chemoradiotherapy to surgical treatment reduced the local recurrence rates to $11 \%$ in the GITSG and $16 \%$ in the National Surgical Adjuvant Breast and Bowel Project (NSABP) R-01 studies [3, 4]. In 1990, the National Cancer Institute Consensus Conference in the USA recommended chemoradiotherapy after the surgical resection of stage II/III rectal cancer [5]. 
In surgical technique, there has also been a remarkable effort to decrease the local recurrence of rectal cancer. The total mesorectal excision (TME) was introduced by Heald and Ryall [6] in 1982 and dramatically reduced the local recurrence rate [7]. The TME has been a standard surgical technique for rectal cancer, but it has been used to treat all levels of rectal cancer so that the anastomotic leakage rate is high. As a result, the tumor-specific mesorectal excision (TSME) technique was introduced to achieve good local control and low morbidity. In the TSME, the conventional TME technique is applied to middle and distal rectal cancer, and a partial mesorectal excision is applied, with sharp dissection through the mesorectal fascia 4 to $5 \mathrm{~cm}$ below the lower border of tumor, to proximal rectal cancer [8-10]. The TSME seems to be a more reasonable technique to reduce the complications caused by anastomotic ischemia, and it has become widespread and is accepted as a standard surgical method for the treatment of rectal cancer.

An optimal treatment modality for rectal cancer should be developed to decrease morbidity and mortality, as well as to increase the survival. The present study analyzed the oncologic outcomes and the prognostic factors after a TSME for stage I to III rectal cancer in order to provide information and evidence for planning the treatment modality of rectal cancer.

\section{METHODS}

\section{Patients}

Between January 1995 and December 2005, 1,017 patients with primary rectal cancer underwent surgical resection in the Department of Surgery, Busan Paik Hospital, Inje University College of Medicine. All patients who had a surgical resection for rectal cancer were registered in a prospectively collected colorectal cancer database and followed up. Seven hundred eighty-two patients with pathologic stage I to III tumors after the TSME were included in this study. Patients with distant metastasis, palliative resection, or no information about preoperative serum carcinoembryonic antigen (CEA) level or the distance from the anal verge (AV) were excluded. Rectal cancer was defined by sigmoidoscopy as a tumor with a lower border within $15 \mathrm{~cm}$ of the $\mathrm{AV}$, and histopathologically confirmed adenocarcinoma with invasion of the submucosal layer.

Rectal cancer was classified into three groups by its distance from the AV: distal $(<7 \mathrm{~cm}$ from AV), mid $(7 \mathrm{~cm} \leq$ level $<12 \mathrm{~cm}$ from AV), and proximal (12 cm $\leq$ level $\leq 15 \mathrm{~cm}$ from AV). The survival rate was analyzed using data from the national cancer registry. All patients underwent surgical resection with a laparotomy because laparoscopic surgery has been used for patients with rectal cancer since 2006 at our institution. Anastomotic leakage was defined as definite disruption of anastomosis with high fever, abdominal pain, fecal material drainage, and leukocytosis that required surgical intervention such as a diverting enterostomy. Circumferential resection margin involvement was defined as a distance of $<1 \mathrm{~mm}$ between the outer margin and the mesorectal fascia.

\section{Surgical therapy}

Surgical resection was carried out after preoperative staging by digital rectal examination, rigid sigmoidoscopy, chest X-ray, transrectal ultrasonography (TRUS), and abdominopelvic computed tomography (CT). A low midline incision that extended above the umbilicus was made. The inferior mesenteric artery was doubly ligated at its origin, while carefully preserving the hypogastric nerve plexus. The inferior mesenteric vein was ligated at the same level as the inferior mesenteric artery. A sharp pelvic dissection was performed from the entrance to the pelvic cavity down to the pelvic floor, while preserving both the hypogastric nerve fibers and the pelvic nerve. Sharp pelvic dissections of the posterior and the anterior rectum were performed first, followed by a lateral dissection. Especially in male patients, a more careful dissection around the seminal vesicles was performed to avoid damage to the neurovascular bundle. Dissection of the lateral side of the rectum was done with ligation of the midrectal artery and careful preservation of the pelvic nerve plexus. The mesorectum was cleared completely for middle and distal rectal cancers $(<12 \mathrm{~cm}$ from AV) and was transected at 4 to $5 \mathrm{~cm}$ below the lower tumor margin for proximal rectal cancer (12 to $15 \mathrm{~cm}$ from $\mathrm{AV}$ ). An ultra-low anterior resection was performed with straight coloanal anastomosis. A diverting enterostomy was performed only when the security of the anastomosis was uncertain, such as in cases of poor blood supply, poor bowel preparation, increased anastomotic tension, or positive air leak. An abdominoperineal resection (APR) was performed by using a frozen sectional biopsy during an ultra-low anterior resection when anal sphincter invasion was identified during preoperative evaluation and the distal resection margin was positive for a tumor. In the case of rectal cancer with obstruction or perforation, a TME or a TSME followed by Hartmann's colostomy was performed.

\section{Adjuvant therapy}

Adjuvant therapy was not routinely given to patients with pathologic stage II or III rectal cancer. Postoperative chemoradiotherapy was given to those who had middle or distal rectal cancer only when local surgical control was in doubt, such as in cases of tumor invasion of multiple lymph nodes, lymphovascular invasion, or a suspected positive resection margin. Postoperative chemotherapy was given to those who had proximal rectal cancer with the above risk factors. Chemotherapy was comprised of $425-\mathrm{mg} / \mathrm{m}^{2}$ 5 -fluorouracil for 5 days and $20-\mathrm{mg} / \mathrm{m}^{2}$ leucovorin for 5 days intravenously, monthly for six cycles. Radiotherapy was started with a total of 5,040 cGy external beam radiation in 28 fractions at the beginning of the second cycle of chemotherapy. For proximal rectal cancer, chemotherapy was given only to patients with positive lymph nodes. No adjuvant chemoradiotherapy was administered to patients who refused radiotherapy, were older than 75 years of age, or showed poor performance status. Preoperative chemoradiotherapy was administered only when patients with T3 or T4 stage tumors had bulky and fixed middle or distal rectal cancer, as 
detected by digital rectal examination or sigmoidoscopy.

\section{Follow-up}

Patients were followed up every 3 months for the first 2 years after surgery and every 6 months thereafter for 3 years, for a total of 5 years. History, physical examination, and serum CEA level were determined at each follow-up visit. Chest X-ray and abdominopelvic CT were done at 6-month intervals, and colonoscopy was performed annually. Recurrence was identified by imaging studies and colonoscopy and was confirmed by colonoscopic or percutaneous biopsy. When histologic confirmation was not possible, radiologically-observed tumor growth within the previous surgical field was considered to indicate recurrence.

Table 1. Clinical characteristics

\begin{tabular}{|c|c|}
\hline Characteristic & №. $(\%)$ \\
\hline \multicolumn{2}{|l|}{ Sex } \\
\hline Male & $421(53.84)$ \\
\hline Female & $361(46.16)$ \\
\hline \multicolumn{2}{|l|}{ Age (yr) } \\
\hline Mean (SD) (range) & 58.78 (11.34) (27-96) \\
\hline$\leq 59$ & $355(45.40)$ \\
\hline$\geq 60$ & $427(54.60)$ \\
\hline \multicolumn{2}{|l|}{ Distance from AV (cm) } \\
\hline Mean (SD) (range) & $7.3(3.36)(1-15)$ \\
\hline \multicolumn{2}{|l|}{ Serum CEA level (ng/mL) } \\
\hline Preoperative mean (SD) (range) & 11.22 (33.85) (0.10-624) \\
\hline$\leq 5$ & $552(70.59)$ \\
\hline$>5$ & $230(29.41)$ \\
\hline \multicolumn{2}{|l|}{ Tumor size (cm) } \\
\hline Mean (SD) (range) & $4.83(2.03)(0.5-13)$ \\
\hline \multicolumn{2}{|l|}{ Operation type } \\
\hline APR & 217 (27.75) \\
\hline LAR & $526(67.26)$ \\
\hline uLAR & $13(1.66)$ \\
\hline Hartmann & $24(3.07)$ \\
\hline Other & $2(0.26)$ \\
\hline Diverting colostomy & $77(9.93)$ \\
\hline Anastomotic leakage & $14(1.79)$ \\
\hline \multicolumn{2}{|l|}{ Adjuvant treatment } \\
\hline Preoperative CRT & $31(3.96)$ \\
\hline Postoperative CRT & 177 (22.63) \\
\hline Postoperative CTx & $90(11.5)$ \\
\hline
\end{tabular}

AV, anal verge; CEA, carcinoembryonic antigen; APR, abdominoperineal resection; LAR, low anterior resection; ULAR, ultra-low anterior resection; CRT, chemoradiotherapy; CTx, chemotherapy.

\section{Statistical analysis}

Statistical analyses were performed using SAS ver. 9.2 (SAS Institute Inc., Cary, NC, USA). The $\chi^{2}$ test was used to analyze categorical variables, and the student's t-test was used for continuous variables. Survival was analyzed using the Kaplan-Meier method. The prognostic factors for survival and recurrence were analyzed with the log-rank test. Multivariate analyses were performed with the Cox proportional hazard model. P-values of less than 0.05 were considered statistically significant.

\section{RESULTS}

\section{Clinical and pathologic characteristics}

Of the 782 patients, 421 (53.84\%) were male, and 361 (46.16\%) were female. The median age was 58.78 years (range, 27 to 96 years). The median distance of the tumor from the AV was $7.3 \mathrm{~cm}$ (range, 1 to $15 \mathrm{~cm}$ ). For the surgical procedure, 217 patients $(27.75 \%)$ underwent an APR, 526 (67.26\%) a low anterior resection, 13 (1.66\%) an ultra-low anterior resection, and 24 (3.07\%) Hartmann's opera-

Table 2. Histopathologic characteristics

\begin{tabular}{|c|c|}
\hline Characteristic & No. $(\%)$ \\
\hline \multicolumn{2}{|c|}{ Histologic differentiation } \\
\hline Well & $127(16.24)$ \\
\hline Moderate & $603(77.10)$ \\
\hline Poor & $16(2.05)$ \\
\hline Mucinous & $35(4.48)$ \\
\hline Signet ring cell & $1(0.13)$ \\
\hline \multicolumn{2}{|c|}{ Lymphovascular invasion } \\
\hline Positive & $287(36.70)$ \\
\hline \multicolumn{2}{|c|}{ Circumferential resection margin } \\
\hline Involved & $51(6.52)$ \\
\hline \multicolumn{2}{|l|}{ Distal margin (cm) } \\
\hline Mean (SD) (range) & $2.19(1.83)(0.1-13)$ \\
\hline \multicolumn{2}{|l|}{ Distal resection margin } \\
\hline Involved & $7(0.90)$ \\
\hline \multicolumn{2}{|l|}{ AJCC stage } \\
\hline I & $177(22.63)$ \\
\hline$\| \mathrm{A}$ & 247 (31.59) \\
\hline$\| \mathrm{B}$ & $6(0.77)$ \\
\hline$\| I A$ & $25(3.20)$ \\
\hline$\|I\| B$ & $166(21.23)$ \\
\hline$\| I I C$ & $161(20.59)$ \\
\hline Stage I & $177(22.63)$ \\
\hline Stage II & $253(32.35)$ \\
\hline Stage III & $352(45.01)$ \\
\hline
\end{tabular}

AJCC, American Joint Committee on Cancer. 
tion. Anastomotic leakage after surgery was seen in 14 patients (1.79\%). Preoperative chemoradiotherapy was performed in 31 patients $(3.96 \%)$ and postoperative chemoradiotherapy in 177 patients $(22.63 \%)$; 90 patients $(11.5 \%)$ were treated only with postoperative chemotherapy (Table 1$)$. The mean follow-up period was $61 \pm 31$ months, and follow-up loss was 193 (24.9\%).

Histopathologic characteristics are shown in Table 2. Adenocarcinomas were well-differentiated in 127 patients (16.24\%), moderately differentiated in $603(77.10 \%)$, poorly differentiated in 16 (2.05\%), mucinous in 35 (4.48\%), and signet ring cell in one $(0.13 \%)$. On histopathologic examination, vascular or lymphatic invasion was positive in 287 patients (36.7\%); 7 patients (0.9\%) showed distal resection margin involvement, and 51 (6.52\%) showed circumferential resection margin involvement. The American Joint Committee on Cancer (AJCC) system was used for staging, yielding the final pathologic tumor stages: stage I, 177 patients (22.63\%); stage II, 253 patients (32.35\%); and stage III, 352 patients (45.01\%).

\section{Analysis of local and systemic recurrence}

Local recurrence occurred in 72 patients (9.21\%), with 30 cases (3.84\%) in a previous anastomotic site, 23 cases $(2.94 \%)$ in the pelvic cavity, and 14 cases (1.79\%) in the presacral area (Table 3 ). Five-year local recurrence rates according to stage were $1.7 \%$ in stage I, $5.0 \%$ in stage II, and $10.8 \%$ in stage III ( $\mathrm{P}=0.002)$ (Fig. 1). In the univariate analysis, the risk factors for local recurrence were age $(\mathrm{P}=0.046)$, pT stage $(\mathrm{P}=0.018)$, $\mathrm{pN}$ stage $(\mathrm{P}<0.001)$, lymphovascular invasion $(\mathrm{P}=0.006)$, positive distal resection margin $(\mathrm{P}<0.001)$, and positive circumferential resection margin $(\mathrm{P}<$

Table 3. Patterns of recurrence

\begin{tabular}{lr}
\hline Site & No. (\%) \\
\hline Local recurrence & $30(3.84)$ \\
Anastomotic & $23(2.94)$ \\
Pelvic & $14(1.79)$ \\
Presacral & $3(0.38)$ \\
Bladder & $2(0.26)$ \\
Perineal & $72(9.21)$ \\
Total & \\
Systemic recurrence & $62(7.93)$ \\
Lung & $45(5.75)$ \\
Liver & $24(3.07)$ \\
Bone & $9(1.15)$ \\
Paraaortic lymph node & $8(1.02)$ \\
Peritoneal seeding & $4(0.51)$ \\
Inguinal lymph node & $3(0.38)$ \\
Brain & $10(1.28)$ \\
Others & $165(21.10)$ \\
\hline Total & \\
\hline
\end{tabular}

0.001) (Table 4). However, the multivariate analysis found that $\mathrm{pN}$ stage $(P=0.015)$, positive distal resection margin $(P<0.001)$, and positive circumferential resection margin $(\mathrm{P}<0.001)$ were independent risk factors for local recurrence (Table 4$)$. Systemic recurrence occurred in 165 patients (21.1\%), including 62 cases $(7.93 \%)$ of lung metastasis, 45 cases (5.75\%) of liver metastasis, and 24 cases (3.07\%) of bone metastasis (Table 3). Five-year systemic recurrence rates according to AJCC stage were $0 \%$ in stage I, $13 \%$ in stage II, and $33.7 \%$ in stage III. Recurrence increased significantly with increasing stage (Fig. 2). In the univariate analysis, the risk factors for systemic recurrence were $\mathrm{pT}$ stage $(\mathrm{P}<0.001)$, $\mathrm{pN}$ stage $(\mathrm{P}<$ $0.001)$, elevated preoperative serum CEA level $(\mathrm{P}<0.001)$, histologic grade $(\mathrm{P}=0.049)$, lymphovascular invasion $(\mathrm{P}<0.001)$, and positive circumferential resection margin $(\mathrm{P}=0.0112)$ (Table 4). In the multivariate analysis, $\mathrm{pN}$ stage $(\mathrm{P}<0.001)$ and preoperative serum CEA level $(P=0.006)$ were independent risk factors for systemic recurrence (Table 4 ).

\section{Analysis of survival rates and prognostic factors}

The 5-year cancer-specific survival rate was $77.53 \%$ and decreased significantly with increasing stage: $97.7 \%$ in stage I; $83 \%$ in stage II; and $61.33 \%$ in stage III (Fig. 3). In the univariate analysis, the risk factors for the 5-year cancer-specific survival rate were $\mathrm{pT}$ stage $(\mathrm{P}<$ $0.001)$, pN stage $(\mathrm{P}<0.001)$, preoperative serum $\mathrm{CEA}$ level $(\mathrm{P}=$ $0.003)$, lymphovascular invasion $(\mathrm{P}<0.001)$, positive distal resection margin $(\mathrm{P}<0.001)$, and positive circumferential resection margin $(\mathrm{P}<0.001)$ (Table 4$)$. In the multivariate analysis, $\mathrm{pT}$ stage $(\mathrm{P}<0.001)$, $\mathrm{pN}$ stage $(\mathrm{P}<0.001)$, positive distal resection margin $(\mathrm{P}<0.001)$, and positive circumferential resection margin $(\mathrm{P}=$ 0.016) were independent risk factors for the 5-year cancer-specific survival rate (Table 4).

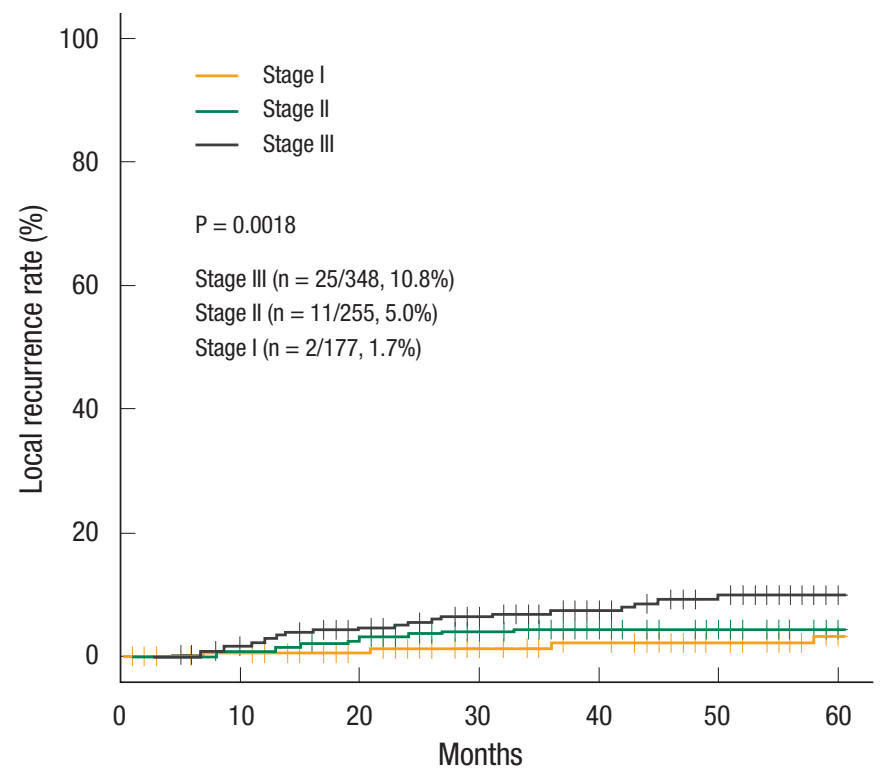

Fig. 1. Local recurrence rates according to pathologic tumor stage. 
Oncologic Outcomes and Risk Factors for Recurrence after Tumor-specific Mesorectal Excision of Rectal Cancer: 782 Cases

Coloproctology sam Hee Kim, et al.

Table 4. Analysis of prognostic factors

\begin{tabular}{|c|c|c|c|c|c|c|c|c|c|}
\hline \multirow[b]{2}{*}{ Factor } & \multicolumn{3}{|c|}{ Local recurrence } & \multicolumn{3}{|c|}{ Systemic recurrence } & \multicolumn{3}{|c|}{ Cancer-specific survival } \\
\hline & $5-$ Year $^{\mathrm{a}}$ & $\begin{array}{c}\text { Uni- } \\
\text { variate }^{\text {b }}\end{array}$ & $\begin{array}{c}\text { Multi- } \\
\text { variate }^{c}\end{array}$ & 5 -Year $^{\mathrm{a}}$ & $\begin{array}{c}\text { Uni- } \\
\text { variate }^{b}\end{array}$ & $\begin{array}{c}\text { Multi- } \\
\text { variate }^{c}\end{array}$ & 5 -Year ${ }^{\mathrm{a}}$ & $\begin{array}{c}\text { Uni- } \\
\text { variate }^{b}\end{array}$ & $\begin{array}{l}\text { Multi- } \\
\text { variate }^{c}\end{array}$ \\
\hline Male & 7.12 & 0.529 & & 19.92 & 0.594 & & 75.89 & 0.281 & \\
\hline Female & 5.60 & & & 17.90 & & & 79.40 & & \\
\hline$>60$ & 8.32 & & & 16.96 & & & 78.93 & & \\
\hline \multicolumn{10}{|l|}{ pT } \\
\hline pT1 & 0 & 0.018 & 0.092 & 0 & $<0.001$ & 0.103 & 98.41 & $<0.001$ & $<0.001$ \\
\hline pT2 & 2.95 & & & 4.27 & & & 93.83 & & \\
\hline pNO & 3.67 & $<0.001$ & 0.015 & 7.53 & $<0.001$ & $<0.001$ & 89.65 & $<0.001$ & $<0.001$ \\
\hline pN1 & 6.43 & & & 24.26 & & & 72.42 & & \\
\hline pN2 & 17.87 & & & 45.01 & & & 49.71 & & \\
\hline \multicolumn{10}{|l|}{ Preoperative CEA (ng/mL) } \\
\hline$\leq 5$ & 6.60 & 0.646 & & 15.37 & $<0.001$ & 0.005 & 80.05 & 0.003 & 0.103 \\
\hline$>5$ & 6.58 & & & 28.04 & & & 69.87 & & \\
\hline \multicolumn{10}{|l|}{ Histologic type } \\
\hline Well differentiated & 5.09 & 0.680 & & 8.09 & 0.049 & 0.438 & 84.14 & 0.084 & 0.498 \\
\hline Moderately differentiated & 6.66 & & & 21.02 & & & 77.57 & & \\
\hline$\geq 13$ & 5.50 & & & 20.97 & & & 82.48 & & \\
\hline Lymphovascular invasion & & 0.006 & 0.106 & & $<0.001$ & 0.843 & & $<0.001$ & 0.598 \\
\hline$(-)$ & 4.18 & & & 14.71 & & & 82.46 & & \\
\hline$(+)$ & 10.87 & & & 26.70 & & & 68.57 & & \\
\hline \multicolumn{10}{|l|}{ Distal resection margin } \\
\hline 0 & 6.19 & $<0.001$ & $<0.001$ & 19.06 & 0.425 & & 77.18 & $<0.001$ & $<0.001$ \\
\hline 1 & 31.43 & & & 0 & & & 42.86 & & \\
\hline \multicolumn{10}{|c|}{ Circumferential resection margin } \\
\hline 0 & 5.21 & $<0.001$ & $<0.001$ & 18.10 & 0.009 & 0.348 & 78.81 & $<0.001$ & 0.016 \\
\hline 1 & 26.47 & & & 32.73 & & & 49.09 & & \\
\hline \multicolumn{10}{|l|}{ Anastomo-tic leakage } \\
\hline 0 & 6.36 & 0.479 & & 18.96 & 0.750 & & 76.79 & 0.966 & \\
\hline 1 & 11.11 & & & 21.25 & & & 80.00 & & \\
\hline
\end{tabular}

CEA, carcinoembryonic antigen.

a5-Year recurrence rate; bUnivariate analysis (P-value); 'Multivariate analysis (P-value). 


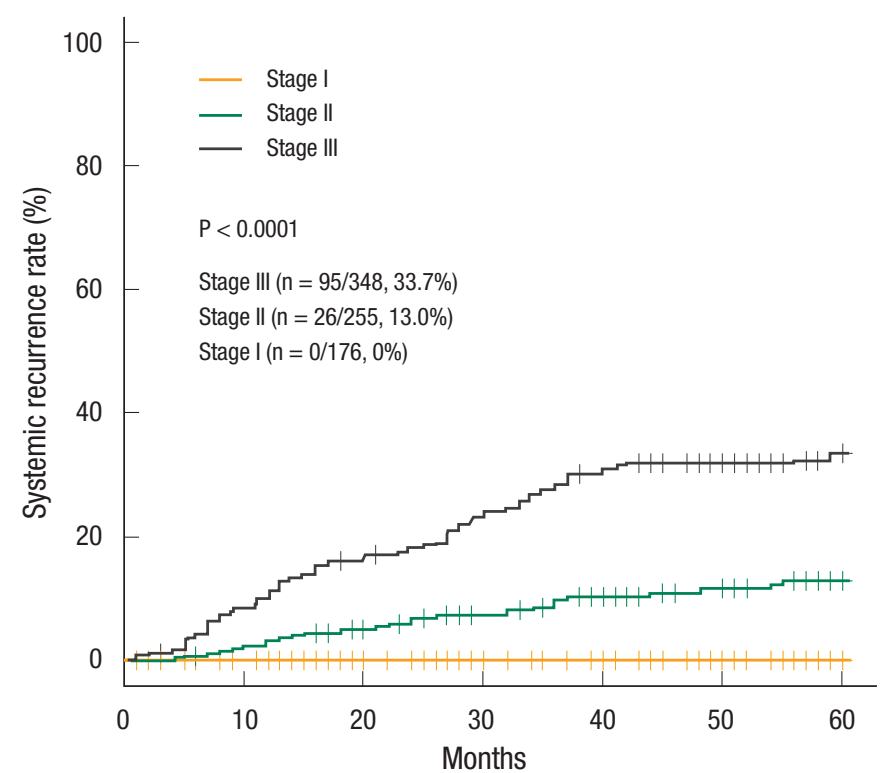

Fig. 2. Systemic recurrence rates according to pathologic tumor stage.

\section{DISCUSSION}

The ideal treatment for rectal cancer should maximize sphincter preservation and lead to optimal oncologic outcomes characterized by low morbidity and mortality. In this study, the oncologic outcomes after a TSME of rectal cancer showed a 77.5\% 5-year cancer-specific survival rate, a 9.2\% local recurrence rate, and a $21.1 \%$ systemic recurrence rate.

For the past 20 years, the results of treatment for rectal cancer have improved in terms of local recurrence and cancer-specific survival rates due to adjuvant chemoradiotherapy and optimized surgical techniques. The TME has reduced the local recurrence rate from 20 to $30 \%[1,2]$ to 5 to $7 \%[11,12]$. Adjuvant chemoradiotherapy after a curative resection of rectal cancer reduced the local recurrence rate from 24 to $11 \%$ in the GITSG study and from 25 to $16 \%$ in the NSABP R-01 study [3, 4]. In 1990, these two randomized trials prompted a National Cancer Institute Consensus Conference in the USA to recommend postoperative adjuvant chemoradiotherapy for patients with T3-stage rectal cancer, involvement of lymph nodes, or both [5]. However, efforts to optimize the surgical technique led to the TME being changed to the TSME because the TME had a high morbidity associated with an anastomotic leakage rate of $23.5 \%$ [7-10, 13]. In the TSME, a TME is performed for middle and distal rectal cancer, and a partial mesorectal excision with sharp pelvic dissection is performed for proximal rectal cancer. The TSME has been associated with a local recurrence rate of $9.2 \%$ at our institution, which is comparable to another TSME study, with a rate of $9.7 \%$, reported by Law and Chu [13], but unfavorable compared with the $5.4 \%$ rate reported by Kim et al. [14]. This difference seems to be due to the application of adjuvant chemoradiotherapy, which was performed in all

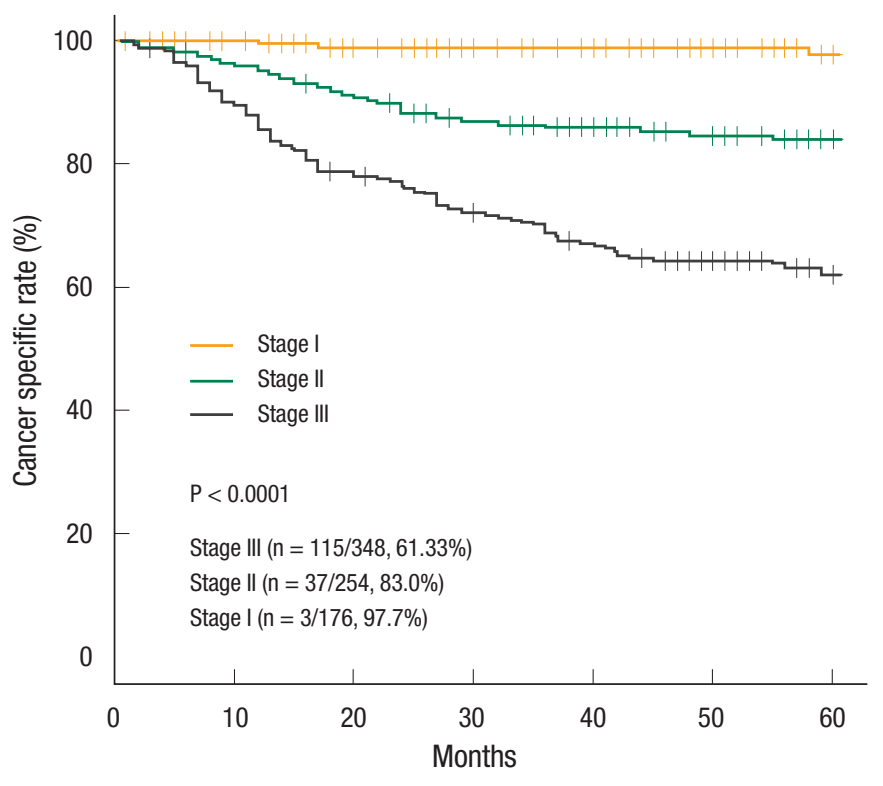

Fig. 3. Cancer-specific survival rates according to pathologic tumor stage.

patients with postoperative pathologic stages exceeding II in the study of Kim et al. [14], but was not routinely performed for patients in the study of Law and Chu [13]; in the latter series, adjuvant chemoradiotherapy was performed only when local clearance was in doubt. In the present study, we did not perform adjuvant chemoradiotherapy in any patient with a tumor stage exceeding stage II; rather, we used it almost postoperatively in selective patients with multiple lymph-node invasion, lymphovascular invasion, or suspected positive resection margins. Thus, the slightly high rate of local recurrence seemed to be caused by not routinely administering adjuvant chemoradiotherapy after the TSME. Therefore, the use of adjuvant chemoradiotherapy in all patients with tumor stages exceeding stage II would be helpful to improve the local recurrence rate after a TSME. In 2004, the German Rectal Cancer Trial [15] compared the applications of preoperative and postoperative chemoradiotherapy, and reported a 13\% 5-year local recurrence rate after postoperative treatment and a $6 \%$ rate after preoperative treatment. Thus, in 2009, the National Comprehensive Cancer Network guidelines designated preoperative chemoradiotherapy as a standard therapy in clinical stage II/III patients with suspected lymph-node invasion and cT3 stage [16]. In the present study, we found that $\mathrm{pN}$ stage, positive distal resection margin, and positive circumferential resection margin were independent risk factors for local recurrence. These factors are similar to those of other TME studies [13, 17-19], so if these risk factors are predicted in the preoperative magnetic resonance image or TRUS, more aggressive NCRT should be performed with the TSME. However, for effective use of NCRT, more accurate diagnostic tools are needed for predicting risk factors, which include positive lymph nodes, circumferential resection involvement, and anal sphincter involvement, because a patient with a lower stage than expected 
or with no risk factors could be over-treated. Also, predictive factors for response to NCRT should be developed because patients with disease during NCRT would be treated by using a useless method. Kim et al. [14] suggested that preoperative chemoradiotherapy would be better in patients with rectal cancer localized in the distal rectum and in high-risk patients such as those with a positive circumferential resection margin and invasion of the anal sphincter. Until more accurate diagnostic tools and predictive factors for response to NCRT are developed, the suggestion of Kim et al. [14] could provide good selective indications for effective use of NCRT.

The rates of systemic recurrence have been reported to be 16.3 to $22.1 \%$, which are similar to our present results [14, 20-22]. Known risk factors for systemic recurrence include sex, tumor stage, circumferential resection margin, and preoperative serum CEA level $[14,17,22]$. In the present study, the multivariate analysis revealed that the risk factors for systemic recurrence were $\mathrm{pN}$ stage and preoperative serum CEA level. Systemic adjuvant chemotherapy should also be considered when these factors are detected, and more effective regimens, such as the adjuvant chemotherapeutic regimens for colon cancer should be tried.

Our analysis of 782 cases of rectal cancer with pathologic stage I to III cancer after a TSME found a 5-year cancer-specific survival rate of $77.5 \%$, a local recurrence rate of $9.2 \%$, and a systemic recurrence rate of $21.1 \%$. The risk factors affecting the cancer-specific survival rate were $\mathrm{pT}$ stage, $\mathrm{pN}$ stage, positive distal resection margin, and positive circumferential resection margin. The risk factors affecting local recurrence were $\mathrm{pN}$ stage, positive distal resection margin, and positive circumferential resection margin. The risk factors affecting systemic recurrence were $\mathrm{pN}$ stage and preoperative CEA level.

In conclusion, the oncologic outcomes at our institution after a TSME for patients with resectable rectal cancer were similar to those reported in other recent studies, and we established the risk factors that could be crucial for the planning of treatment and follow-up.

\section{CONFLICT OF INTEREST}

No potential conflict of interest relevant to this article was reported.

\section{REFERENCES}

1. Hermanek P, Wiebelt H, Staimmer D, Riedl S. Prognostic factors of rectum carcinoma: experience of the German Multicentre Study SGCRC. German Study Group Colo-Rectal Carcinoma. Tumori 1995;81(3 Suppl):60-4.

2. Douglass HO Jr, Moertel CG, Mayer RJ, Thomas PR, Lindblad AS, Mittleman A, et al. Survival after postoperative combination treatment of rectal cancer. N Engl J Med 1986;315:1294-5.

3. Thomas PR, Lindblad AS. Adjuvant postoperative radiotherapy and chemotherapy in rectal carcinoma: a review of the Gastroin- testinal Tumor Study Group experience. Radiother Oncol 1988;13: 245-52.

4. Fisher B, Wolmark N, Rockette H, Redmond C, Deutsch M, Wickerham DL, et al. Postoperative adjuvant chemotherapy or radiation therapy for rectal cancer: results from NSABP protocol R-01. J Natl Cancer Inst 1988;80:21-9.

5. NIH consensus conference. Adjuvant therapy for patients with colon and rectal cancer. JAMA 1990;264:1444-50.

6. Heald RJ, Ryall RD. Recurrence and survival after total mesorectal excision for rectal cancer. Lancet 1986;1:1479-82.

7. Krook JE, Moertel CG, Gunderson LL, Wieand HS, Collins RT, Beart RW, et al. Effective surgical adjuvant therapy for high-risk rectal carcinoma. N Engl J Med 1991;324:709-15.

8. Scott N, Jackson P, al-Jaberi T, Dixon MF, Quirke P, Finan PJ. Total mesorectal excision and local recurrence: a study of tumour spread in the mesorectum distal to rectal cancer. Br J Surg 1995;82:1031-3.

9. Joh NS, Kim NK, Yun SH, Kim HG, Min JS. Lymph node metastases and tumor deposits in the mesorectum distal to rectal cancer: a need of total mesorectal excision. J Korean Soc Coloproctol 1999;15:273-9.

10. Hida J, Yasutomi M, Maruyama T, Fujimoto K, Uchida T, Okuno $\mathrm{K}$. Lymph node metastases detected in the mesorectum distal to carcinoma of the rectum by the clearing method: justification of total mesorectal excision. J Am Coll Surg 1997;184:584-8.

11. Heald RJ, Husband EM, Ryall RD. The mesorectum in rectal cancer surgery: the clue to pelvic recurrence? Br J Surg 1982;69:613-6.

12. Arbman G, Nilsson E, Hallbook O, Sjodahl R. Local recurrence following total mesorectal excision for rectal cancer. Br J Surg 1996;83:375-9.

13. Law WL, Chu KW. Anterior resection for rectal cancer with mesorectal excision: a prospective evaluation of 622 patients. Ann Surg 2004;240:260-8.

14. Kim NK, Min BS, Kim JS, Hur H, Lee KY, Sohn SK, et al. Oncologic outcomes and safety after tumor-specific mesorectal excision for resectable rectal cancer: a single institution's experience with 1,276 patients with rectal cancer. J Korean Soc Coloproctol 2008;24:121-33.

15. Sauer R, Becker H, Hohenberger W, Rodel C, Wittekind C, Fietkau R, et al. Preoperative versus postoperative chemoradiotherapy for rectal cancer. N Engl J Med 2004;351:1731-40.

16. Engstrom PF, Arnoletti JP, Benson AB 3rd, Chen YJ, Choti MA, Cooper HS, et al. NCCN Clinical Practice Guidelines in Oncology: rectal cancer. J Natl Compr Canc Netw 2009;7:838-81.

17. Wibe A, Syse A, Andersen E, Tretli S, Myrvold HE, Soreide O, et al. Oncological outcomes after total mesorectal excision for cure for cancer of the lower rectum: anterior vs. abdominoperineal resection. Dis Colon Rectum 2004;47:48-58.

18. Law WL, Chu KW. Local recurrence following total mesorectal excision with double-stapling anastomosis for rectal cancers: analysis of risk factors. World J Surg 2002;26:1272-6.

19. Peeters KC, Marijnen CA, Nagtegaal ID, Kranenbarg EK, Putter $\mathrm{H}$, Wiggers $\mathrm{T}$, et al. The TME trial after a median follow-up of 6 
years: increased local control but no survival benefit in irradiated patients with resectable rectal carcinoma. Ann Surg 2007;246: 693-701.

20. Andreoni B, Chiappa A, Bertani E, Bellomi M, Orecchia R, Zampino $\mathrm{M}$, et al. Surgical outcomes for colon and rectal cancer over a decade: results from a consecutive monocentric experience in 902 unselected patients. World J Surg Oncol 2007;5:73.
21. Zaheer S, Pemberton JH, Farouk R, Dozois RR, Wolff BG, Ilstrup D. Surgical treatment of adenocarcinoma of the rectum. Ann Surg 1998;227:800-11.

22. Park IJ, Kim HC, Yu CS, Kim JC. Pattern of recurrences and metastases after a curative resection for primary colorectal cancer. J Korean Soc Coloproctol 2008;24:207-13. 